\title{
Molecular impact of launch related dynamic vibrations and static hypergravity in planarians
}

\author{
Nídia de Sousa (10) ${ }^{1}$, Marcello Caporicci ${ }^{2}$, Jeroen Vandersteen ${ }^{3}$, Jose Ignacio Rojo-Laguna ${ }^{1}$, Emili Saló ${ }^{2}$, Teresa Adell ${ }^{1}$, \\ Gennaro Auletta ${ }^{4,5}$ and Jack J.W.A. van Loon $\mathbb{1 0}^{2,6 \bowtie}$
}

\begin{abstract}
Although many examples of simulated and real microgravity demonstrating their profound effect on biological systems are described in literature, few reports deal with hypergravity and vibration effects, the levels of which are severely increased during the launch preceding the desired microgravity period. Here, we used planarians, flatworms that can regenerate any body part in a few days. Planarians are an ideal model to study the impact of launch-related hypergravity and vibration during a regenerative process in a "whole animal" context. Therefore, planarians were subjected to 8.5 minutes of $4 \mathrm{~g}$ hypergravity (i.e. a human-rated launch level) in the Large Diameter Centrifuge (LDC) and/or to vibrations $\left(20-2000 \mathrm{~Hz}, 11.3 \mathrm{G}_{\mathrm{rms}}\right)$ simulating the conditions of a standard rocket launch. The transcriptional levels of genes (erg-1, runt-1, fos, jnk, and yki) related with the early stress response were quantified through qPCR. The results show that early response genes are severely deregulated after static and dynamic loads but more so after a combined exposure of dynamic (vibration) and static (hypergravity) loads, more closely simulating real launch exposure profiles. Importantly, at least four days after the exposure, the transcriptional levels of those genes are still deregulated. Our results highlight the deep impact that short exposures to hypergravity and vibration have in organisms, and thus the implications that space flight launch could have. These phenomena should be taken into account when planning for wellcontrolled microgravity studies.
\end{abstract}

npj Microgravity (2020)6:25; https://doi.org/10.1038/s41526-020-00115-7

\section{INTRODUCTION}

There is currently an increased interest in space research and gravity-related sciences, especially since commercial space travels opened broad and new perspectives in medical and physical research, innovative tourism, or even in terms of territorial expansion towards the Moon and Mars. The 2005 NASA initiative to designate the US segment of the International Space Station (ISS) as a US national $\mathrm{lab}^{1-3}$ is in line with this trend. In this scenario, more research is required on the mechanisms of the effect of space flights on the function of cells and organisms. Fluctuations in gravity, vibration, pressure, temperature and radiation are the main parameters to take into account in space flight studies ${ }^{4-6}$. While many examples of how simulated and real microgravity, simulated and real partial gravity, and hypergravity demonstrate their profound effects on biological and physiological systems are found in literature, see for review ${ }^{7-10}$, a limited number of reports deal with specific launch-related hypergravity $^{11-13}$ or vibration ${ }^{13-16}$ effects, the levels of which are severely increased in every space flight during ascent. There are, up till now, no ground-based research reports where the effects of launch vibrations and static $\mathrm{g}$ loads are applied simultaneously.

To learn of the effects of hypergravity and vibration in living organisms, we report on the impact of static and dynamic loads on planarians. Planarian are flatworms with the unique ability to regenerate any missing part of their body, even the head, after amputation $^{17,18}$. Planarians show a centralized nervous system, with an anterior brain to which two nerve cords are connected, two eyes, a digestive system that connects to an evaginable pharynx, and an excretory system ${ }^{18}$. The amazing regenerative ability of planarians is due to the presence of a population of adult stem cells-called neoblasts - that are totipotent, and thus able to give rise to any planarian cell type ${ }^{18-20}$. Planarian plasticity is also visible during their normal homeostasis, since they continuously grow and degrow depending on food availability ${ }^{18,21}$. The presence of these unique adult stem cells and their plasticity renders planarians in a unique model to study the impact of environmental factors like hypergravity and vibration in adult cells in the context of a "whole animal", in contrast to the partial view inherent to "in vitro" cell cultures. Also, there is an increasing interest to study these animals under various altered gravity conditions ${ }^{22-26}$.

Planarians were subjected to $4 \mathrm{~g}$ hypergravity in the Large Diameter Centrifuge (LDC) and/or to vibration for 8.5 minutes $\left(20-2000 \mathrm{~Hz}, 11.3 \mathrm{G}_{\mathrm{rms}}\right)$, simulating the conditions of a standard human-rated rocket launch. The transcriptional levels of genes related with the early response were quantified through qPCR. The results show that despite planarians regenerate apparently as good as controls, genes that respond just a few hours after wounding (early response genes) are significantly up- or downregulated after the various treatments. Furthermore, the deregulation is higher after the combined exposure of static and dynamic g loads. Importantly, four days after exposure, the transcriptional levels of those genes are still deregulated. These results highlight the deep impact that launch-related hypergravity and vibrational loads can have on cells and whole organisms, and

\footnotetext{
${ }^{1}$ Department of Genetics, Microbiology and Statistics, Institute of Biomedicine, University of Barcelona (IBUB), Barcelona, Spain. ${ }^{2}$ Life Support and Physical Sciences Section (TECMMG), European Space Agency_European Space Research and Technology Centre (ESA-ESTEC), Noordwijk, The Netherlands. ${ }^{3}$ TEC-ECC, European Space Agency—European Space Research and Technology Centre (ESA-ESTEC), Noordwijk, The Netherlands. ${ }^{4}$ Pontifical Gregorian University, Roma, Italy. ${ }^{5}$ University of Cassino, Cassino, Frosinone, Italy. ${ }^{6}$ DESC (Dutch Experiment Support Center), Amsterdam University Medical Center location VUmc and Academic Centre for Dentistry Amsterdam (ACTA), Vrije Universiteit Amsterdam, Department of Oral and Maxillofacial Surgery/Pathology, Amsterdam Movement Sciences, Amsterdam, The Netherlands. ${ }^{凶}$ email: j.vanloon@amsterdamumc.nl
} 
thus the implications for space flights experiment design and logistics.

\section{RESULTS}

Planarians after short-duration vibration and/or $4 \mathrm{~g}$ hypergravity are able to properly regenerate the missing head

In order to verify whether vibration and hypergravity conditions affects planarian regeneration, 1-day-regenerating planarian trunks - the head and the tail were amputated the day before - were loaded into the LDC in which a vibration system was adapted (Figs. 1a and 2).

To explore the effects of hypergravity and vibration individually and combined, four animal groups were included: planarians at $1 \mathrm{~g}$ without vibration (control group), planarians at $4 \mathrm{~g}$ without vibration, planarians at $1 \mathrm{~g}$ with vibration, and planarians at $4 \mathrm{~g}$ with vibration (see Fig. $1 \mathrm{~b}$ ). In vivo observation of the animals immediately after the treatment $(0 \mathrm{~h})$ and 4 days ( $4 \mathrm{~d})$ after showed no obvious difference in the regenerative abilities between the various planarian groups (Fig. 3). Thus, planarians under vibration and/or $4 \mathrm{~g}$ hypergravity, regenerate an apparently proper head. a
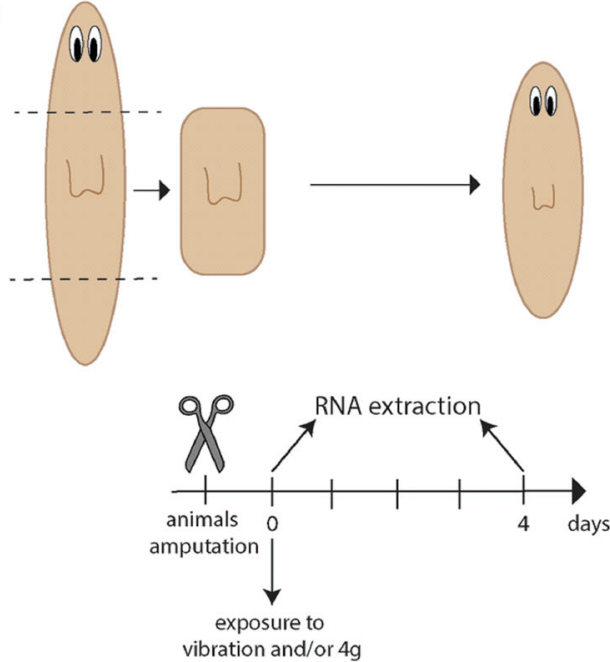

b

\begin{tabular}{c|c}
\multicolumn{2}{c}{$\begin{array}{c}\text { Different groups analyzed in the } \\
\text { experiment }\end{array}$} \\
\hline No vibration / 1g & Control \\
\hline No vibration / $\mathbf{4 g}$ & Hypergravity \\
\hline Vibration / $\mathbf{g}$ & Vibration \\
\hline Vibration / $\mathbf{4 g}$ & $\begin{array}{c}\text { Hypergravity and } \\
\text { vibration }\end{array}$
\end{tabular}

Fig. 1 Experimental design. a Animals were amputated the day before of the exposure to simulated launch loads (day -1). At day 0, animals were loaded into T25 flasks and the experiment was initiated. Immediately after the exposure to hypergravity, vibration or both, RNA was extracted from half of the animals $(0 \mathrm{~h})$. Four days after the exposure, the RNA of the rest of the animals was extracted (4d). The regenerated structures were imaged at 4 days after the exposure. $\mathbf{b}$ The four experimental groups of animals.
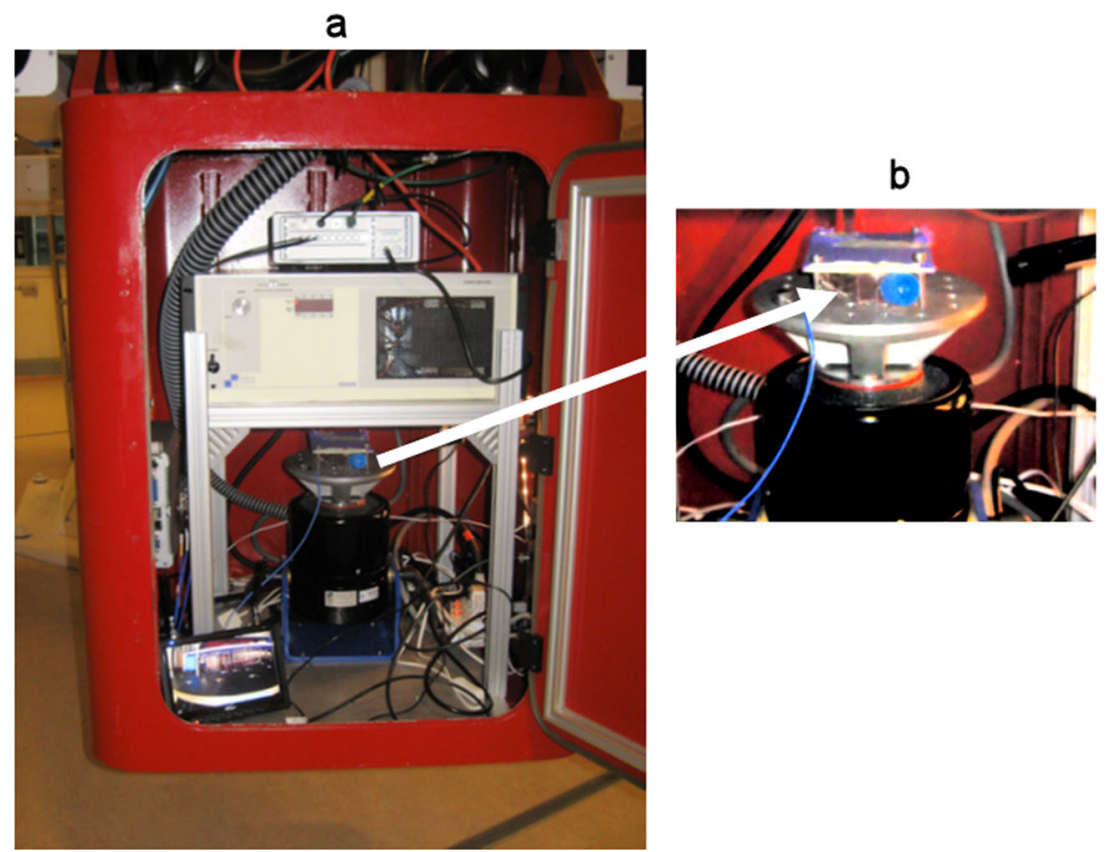

Fig. 2 Vibration system. a Inside of the LDC gondola the vibration system consisting of the actuator, the amplifier and the data acquisition system was mounted in one gondola. The cooling system was placed in a second gondola (not visible in the image). $\mathbf{b}$ Detail of the top part of the actual actuator shown here with a T25 flask attached which contained five animals. The flasks were completely filled with planarian artificial medium, leaving no air bubbles. During simulated launch exposures the animals were at ambient conditions. During other periods the temperatures were $20-22^{\circ} \mathrm{C}$. 
Planarians after short-duration vibration and/or $4 \mathrm{~g}$ hypergravity show a transcriptomic deregulation of genes essential for regeneration

In planarians, the onset of regeneration relies on the transcriptional activation of early response genes, which are known to be quickly activated after any kind of wound. Those genes are essential for the proper proliferation and differentiation of stem cells after an injury ${ }^{27,28}$ in order to restore the missing structures. We performed a qPCR analysis to explore the expression levels of specific early response genes in the animals corresponding to the four conditions studied. We analyzed the expression of the transcription factors runt-1, which is normally expressed $3-6 \mathrm{~h}$ after wounding and is required for specifying different cell types during regeneration ${ }^{27,28}$ and egr-1 (early growth response-1), which is expressed $1 \mathrm{~h}$ after wounding ${ }^{27}$ (Fig. 4). We also analyzed the expression of JNK pathway-related genes (fos-1, jnk), which coordinate the apoptotic and the mitotic response required for proper regeneration ${ }^{29}$ (Fig. 4). Our results show that immediately after the exposure $(0 \mathrm{~h})$ planarians that were subjected to only a static load of $4 \mathrm{~g}$ show a significant decrease in the transcriptional levels of egr-1 and jnk. Planarians which were subjected to only a dynamic load of a random vibration showed a significant increase in the transcriptional levels of egr-1 and a decrease of jnk. The most interesting result was that the simultaneous exposure of planarians to $4 \mathrm{~g}$ hypergravity and vibration severely affected the transcription of the early genes. Thus, five genes analyzed were significantly up- or down-regulated with respect to controls. The two genes related with the JNK pathway (fos and jnk), which are an evolutionarily conserved signal to regulate cell death and cell proliferation in response to injury were the most severely affected. runt- 1 was also up-regulated more than two-fold. In these analyses we also quantified the expression of $y k i$, which is the nuclear

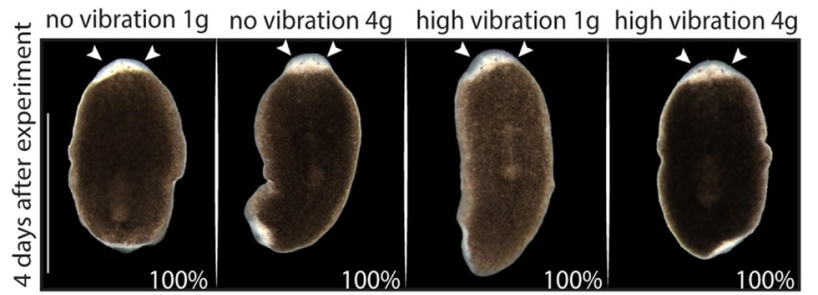

Fig. 3 In vivo phenotype of animals exposed to hypergravity and/ or vibration 4 days after the exposure. Animals in all groups were able to regenerate the head (the eyes are indicated with arrow heads). No alterations are observed between the animals from the four different conditions. $n \geq 10$. Scale bar $=1 \mathrm{~mm}$. effector of the Hippo pathway, involved in tumor progression in mammals and also in planarians ${ }^{30,31}$. Importantly, we show that $y k i$ is significantly down-regulated in samples exposed to vibration and $4 \mathrm{~g}$ (Fig. 4). Maybe the most important result is that four days after the exposure the transcriptional levels of some early genes remained significantly de-regulated in $4 \mathrm{~g}$ hypergravity or vibration alone, and even more so in the samples subjected to simultaneous exposure to static and dynamic loads. However, in the latter samples the levels of de-regulation of fos, were much lower than the initially very high levels observed in the $0 \mathrm{~h}$ samples. It must be also noted that expression levels of piwi, which is a marker of stem cells, does not change in a significant manner in any sample. This result suggests that despite the deregulation of the genes required to respond to stimulus, the organism is able to maintain a stable population of stem cells, which also agrees with the observation that planarians can regenerate properly.

Overall, these results indicate that exposure to static and dynamic loads, similar to the ones experienced during a rocket launch produces a high impact in the transcriptional regulation of genes required to properly respond to any injury. Furthermore, the deregulation is reinforced when both elements, hypergravity and vibration, are applied simultaneously, as it occurs during launch. Importantly, the deregulation of the transcripts occurs immediately after the exposure and persists throughout the following days.

\section{DISCUSSION}

Although planarians regenerate an apparent proper head, our results indicate that short exposures to hypergravity and vibration do elicit important transcriptional changes at a genetic level. The deregulation of the early response genes at $0 \mathrm{~h}$ indicates that the cells are sensing the 'stressing' mechanical stimulus applied and respond by regulating genes that control essential cellular processes as proliferation and cell death. Importantly, although hypergravity or vibration alone already produce transcriptomic alterations, the simultaneous application of both for several minutes produces an even higher alteration of the transcriptional levels of the genes analyzed. The high up-regulation of fos, an oncogene involved in the control of cell death in all animal species ${ }^{32}$, indicates the profound effects that this treatment produces in cells. Even more important is the finding that 4 days after returning the animals to normal $1 \mathrm{~g}$ conditions the transcriptional levels of some genes analyzed do not reach basal levels. In fact, egr-1, and fos show a transcriptional alteration that is inverse with respect to the samples at $0 \mathrm{~h}$, which could indicate that a rebound effect is occurring. Hypergravity or vibration alone
Oh after exposure

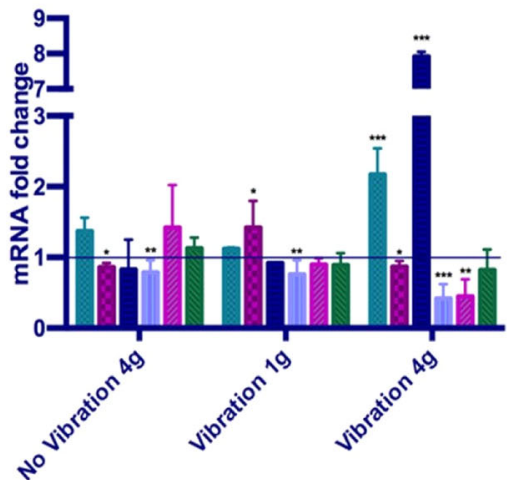

4d after exposure

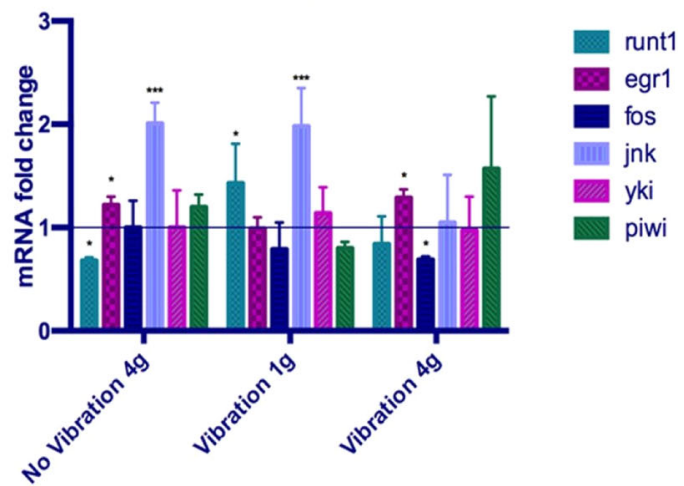

Fig. 4 qPCR analysis of planarians exposed to vibration or/and $\mathbf{4} \mathbf{g}$ hypergravity compared to $\mathbf{1} \mathbf{g}$ static controls directly after exposure or at 4 days post exposure. The mRNA levels of the indicated genes are analyzed with respect to the levels of ura4. Values represent the means of at least two biological replicates each one with five animals. Error bars represent standard deviation. Data was analyzed by two-sided Student's $t$-test. ${ }^{*} p<0.05 ;{ }^{* *} p<0.01 ;{ }^{* * *} p<0.001$. 
are also not completely recovered at 4 days. It must be stressed that these alterations are observed in a context of a "whole animal". Thus, the sustained activation of the early response genes, which main function is to control apoptosis, stem cell proliferation, and differentiation can have an impact in the cell renewal of the organisms affected. The early response genes (cmyc, c-fos) expression after launch-related vibrations was also identified by Tjandrawinata and colleagues ${ }^{33}$ where higher levels of both genes were reported $30 \mathrm{~min}$ after exposure to a one-axis simulated space shuttle launch ( $2 \mathrm{~min} 7.83 \mathrm{G}_{\mathrm{rms}}$ followed by $6 \mathrm{~min}$ at $\left.4.098 G_{\text {rms }}\right)$. However, in that cell monolayer in vitro experiment this increase disappeared after $3 \mathrm{~h}$. Using a whole animal like a planarian provides a more realistic situation where we do not see a recovery even after 4 days.

The study by Kumei and coworkers ${ }^{34}$ was one of the very first published experiments that explored the role hypergravity on the expression of early response genes such as c-fos, c-myc, and c-myb. HeLa cells were exposed for 2-4 days to either 18,35 of $70 \mathrm{~g}$ and only

c-myc showed an increase in expression. In another study, c-fos expression also increased, gradually, in an MC-3T3 bone cell line exposed for $5 \mathrm{~min}$ from 50 to as much as $2000 \mathrm{~g}$, while erg- 1 was more expressed at lower $g$ levels $\mathrm{s}^{35}$. The very first study regarding c-fos in real microgravity showed an opposite effect of gravity. In that paper by de Groot and colleagues they reported a strongly decreased epidermal growth factor (EGF)-induced expression of the $c$-fos and c-jun proto-oncogenes in a Maser sounding rocket experiment ${ }^{36}$. In the preparation for a spaceflight experiment we identified also the possible anabolic effects of vibration providing the opportunity to elucidate how bone cells (MC-3T3) sense vibration stress ${ }^{37}$. More recent studies explored the effects of parabolic flight-related vibrations on thyroid cancer cells ${ }^{13}$ and the possible anabolic effects in chondrocytes ${ }^{38}$.

Comparing launch vibration simulation with in-flight data Cubano and Lewis concluded that the regulation of heat shock proteins $h s p 27$ and $h s p 70$ in Jurkat cells was due to spaceflight ${ }^{15}$. However, based on the current data, it might not be excluded that the effect on $h s p 27$ could also have been generated by the combined effect of vibration and hypergravity loads during launch. Such a combined test was not performed in that study. In spaceflight experiments, the interest is not generally the effect of the launch, but the effect of microgravity specifically. However, the effect of the launch most likely affects the parameters during the next hours or even days. Thus, understanding what happens during the launch is required to optimize the experimental parameters.

Overall, our results indicate that a relatively short exposure to hypergravity and / or vibration can elicit short-term but also longlasting cellular responses on a genetic and likely proteomic level. Even if effects of either static $g$ loads or vibration might have no or little effect separately, paradigms such as stochastic residence might transpose sub-threshold responses to a relevant level ${ }^{39,40}$. It would be interesting to explore the nature of the cellular or tissue responses due to vibration. Would the effects be the result of organelle intracellular replacements like the relatively heavier nucleus ${ }^{37}$ or, also depending on the compliance of the experiment volume, a deformation of the whole-cell/tissue body due to inertial gravitational shear ${ }^{41}$. In this respect, it is worth mentioning that $y k i$ as the effector of the Hippo pathway, which is involved in force transduction of the cellular environment to the nucleus. It has been demonstrated that a direct force on to the cell leads to nuclear translocation of YAP which is the $y k i$ homolog in vertebrates ${ }^{42}$.

The better experimental design in gravity-related space research is to apply an on-board $1 \mathrm{~g}$ centrifuges to control for any spaceflight related effects such as radiation and launch ${ }^{43}$. However, based on current results also the factor time, which is required to fade out launch effects, should also be taken into account by either a delay the in-flight start of an experiment or an implementation of the launch fade out phase by increasing the total active experiment time. This can be combined with the wellestablished reduction of cellular activity by lowering temperature or reducing medium serum content. During a pilot study in preparation of a sounding rocket study we exposed primary osteoblast to an $11 \mathrm{~g}$ launch simulation in the MidiCAR centrifuge at $37^{\circ} \mathrm{C}$. It was shown that cells do sense this profile by phosphorylation of some proteins which could be stopped by 'launching' at $8{ }^{\circ} \mathrm{C}^{44}$.

This study demonstrated the importance of pre-flight tests especially related to launch effects for life sciences/biological experiments. It might be argued that, especially for institutionally funded basic research experiments, one needs, as part of the qualification process, to demonstrate how a particular experiment responds to launch loads (static, dynamic, and combined) and how this relates to the initiation of the experiment while in microgravity. This is especially true for short-duration microgravity experiments that make use of platforms such as parabolic aircraft ${ }^{45}$, drop towers ${ }^{46}$ or sounding rockets but also the more recent commercial suborbital platforms such as the Blue Origin New Shepard ${ }^{47}$, future Virgin Galactic White Knight ${ }^{48}$, Dream Chaser from Sierra Nevada Company ${ }^{49}$ or the upcoming Space Rider from the European Space Agency ${ }^{50}$. It is even more alarming since our data showed that launch effects are visible directly after lift off until even 4 days post exposure. This indicates that although systems like the Russian Soyuz or the Space-X Dragon are now sometimes coupling to the International Space Station within a day, which has always been favored by the life sciences community, an experiment might still need more time to overcome the launch stress effects before a clear and reliable actual microgravity experiment can be initiated.

We may conclude that in this study, where we exposed whole animals to static g-loads and, for the first time, also used combined launch effects with an actuator located inside a large centrifuge, demonstrated the long-lasting effects of launch loads with a limited number of early response genes. Future experiments should explore the full spectrum of genes and proteins relevant for the research of a particular cell, tissue or animal. Also, we applied a generic launch vibration profile in only one axis, while profiles of the various rockets are different and the location, fixation and/or stowage of the samples during launch are very relevant parameters for the actual vibration profile.

We showed that launch effects and especially the combined static g-loads and dynamic vibration, based on our findings concerning expression of five early response gene's expressions can be more important, and long lasting than previously expected. Ideally, any space-flight experiment should be exposed to such launch loads and these tests should be made part of the standard flight-related requirements tests an experiment has to go through before an actual study in real microgravity may be performed and produce relevant results.

\section{METHODS}

Planarian culture and exposure to hypergravity and/or vibration Asexual planarians from a clonal strain of Schmidtea mediterranea BCN-10 were maintained at $20^{\circ} \mathrm{C}$ in planarian artificial medium (PAM) water, as previously described ${ }^{51}$. Animals were fed with veal liver and starved for at least one week before beginning the experiments. Animals were transported from Barcelona/Spain to ESA-ESTEC Noordwijk/the Netherlands in PAM water using $50 \mathrm{~mL}$ falcon tubes.

To study the regeneration process in planarians after exposure to hypergravity and/or vibration animals were amputated (head and tail) one day before the exposure. The day after trunk fragments were loaded into T25 flasks (day 1 of regeneration) (Fig. 1a). Four groups of animals were analyzed: planarians at $1 \mathrm{~g}$ without vibration (control), planarians at four times Earth gravity static accelerations without vibration $(4 \mathrm{~g})$, planarians at $1 \mathrm{~g}$ with dynamic g-loads (vibration), and planarians at $4 \mathrm{~g}$ with vibration 
(Fig. 1B). Three flasks per condition (three replicates), were included with 5 planarians per flask. RNA was extracted from those animals immediately after the exposure $(0 \mathrm{~h})$ and 4 days after (4d).

\section{Simulation of rocket launch}

Planarians were amputated (head and tail) one day before the exposure to launch-related mechanical loads. The day after, trunk fragments were loaded into T25 flasks (day 1 of regeneration). Three T25 flasks were included per condition, and 5 planarians were loaded into each flask. The setup includes the Large Diameter Centrifuge (LDC) (Fig. 5a ref. ${ }^{52}$ ), to simulate hypergravity $(4 \mathrm{~g})$ and a vibration system, which was bolted to the floor plate of one of the gondolas (Fig. 2). The hardware components of the set-up included the actual shaker model 2075E, a linear power amplifier model 2050E09 both from The Modal Shop (TMS, Cincinnati, OH, USA), a front-end 8-channel data acquisition system (LMS / Siemens SCADAS), a cooling system (Asynchronous Motors Cl. 71\2), and a laptop to control the shaker with the companies dedicated control software. To fix the flasks with planarians on the shaker, an aluminum plate wrapped in a thin rubber sheet was used. The rubber sheet impeded the movement of the flasks along the metal plate. Planarians were subjected to vibration and static hypergravity separately or simultaneously. Four groups of animals were analyzed: planarians at $1 \mathrm{~g}$ without vibration (control), planarians at four times Earth's gravitational force static accelerations without vibration $(4 \mathrm{~g})$, planarians at $1 \mathrm{~g}$ with dynamic $\mathrm{g}$-loads (vibration), and planarians at $4 \mathrm{~g}$ with vibration. The parameters used to simulate launch vibration are shown in Fig. $5 \mathrm{~b}$ and Table 1.

The applied vibration profile was based on the Code of Federal Regulations (CRF) of the Office of the Federal Register National Archives and Record Administration, for launches into space from the Federal Aviation Administration (FAA) ${ }^{53}$. These random vibration tests are usually performed at the payload level of assembly for proto-flight hardware that is subjected to a random vibration test to verify its ability to survive the lift-off environment and also to provide a final workmanship vibration test. In this study we applied that same profile to test the biological responses. The total load experienced by the samples is $11.3 G_{\text {rms }}$ in the frequency range between 20 and $2000 \mathrm{~Hz}$ (Table 1, Fig. 5b). These vibration levels are also comparable to the acceptance levels profile of the Generalized Random Vibration Test Levels Components (GELV) for payloads of $22.7 \mathrm{~kg}(50-\mathrm{lb})$ or less with have an overall $G_{\text {rms }}$ of 10.0 as are set in NASA standards ${ }^{54}$.

The vibration was applied for only one of the three orthogonal axes and was slightly modified because the shaker could not output the force required by the profile at higher $g$ levels. In the range from 150 to $600 \mathrm{~Hz}$ we did lower the power from 0.16 to $0.13 \mathrm{~g}^{2} / \mathrm{Hz}$. The force was lessened by $\sim 20$ Newton. Due to the unorthodox application of an actuator inside a centrifuge, and despite the slight adaptation we made, the high vibration at $4 \mathrm{~g}$ ran for $240 \mathrm{~s}(4 \mathrm{~min})$ at maximum intensity and stopped automatically due to reaching the over-heating settings of the system. We immediately restarted the actuator set-up to run for another $270 \mathrm{~s}$ $(4.5 \mathrm{~min})$ in order to complete the full launch time simulation of 8.5 minutes.

\section{Planarian RNA extraction}

To perform the transcriptomic analysis through quantitative real-time PCR (qPCR) analysis, total RNA was extracted from the four groups of planarians immediately $(0 \mathrm{~h})$ and after four days after exposure (4d). Three replicates each containing a pool of five animals were analyzed per condition. RNA was extracted with Trizol (Invitrogen, Carlsbad, CA, USA), following the manufacturer's instructions. RNA was quantified with a Nanodrop ND-1000 spectrophotometer (Thermo Scientific, Waltham, MA, USA) and CDNA was synthesized using SuperScript ${ }^{\mathrm{TM}}$ III Reverse Transcriptase (Thermo Scientific Waltham, MA, USA) following the manufacturer's instructions.

\section{Quantitative real-time PCR}

Quantitative PCR's were performed using Power SYBR ${ }^{T M}$ Green PCR Master Mix (Applied Biosystems) on 7500 Real-Time PCR Systems (Applied a

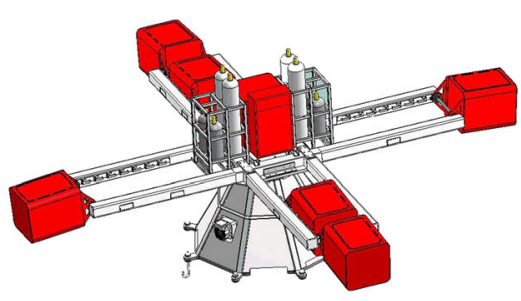

b

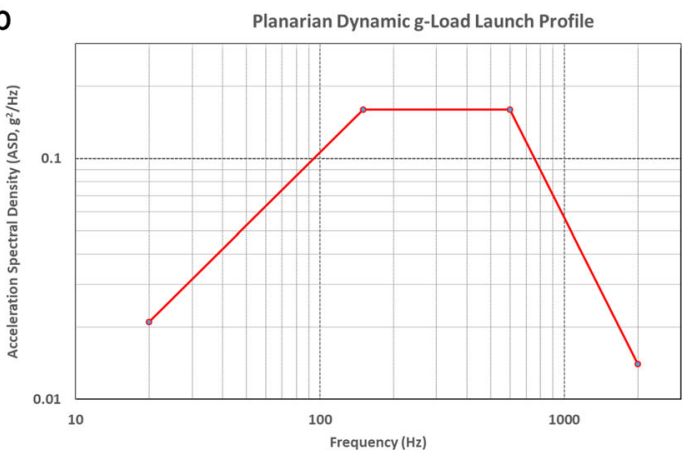

Fig. 5 The six red-colored swing-out and one central gondola from the 8-meter diameter Large Diameter Centrifuge (LDC). a Both centrifuges are currently located at the technology center (ESTEC) from the European Space Agency ESA) in Noordwijk, the Netherlands. b The Acceleration Spectral Density (ASD) of the random vibration test specification profile from the 20 to $2000 \mathrm{~Hz}$ range as used for exposing planarians to a simulated launch load. This profile is based on the minimum workmanship levels for random vibration testing ${ }^{53}$. The equipment set-up was divided over two gondolas where the actual actuator was placed in the outer gondola (see for further details Fig. 2).

Table 1. Vibration parameters, frequency range and power spectral density, as actually used in the dynamic $g$ exposure of planarians for a period of $8.5 \mathrm{~min}$.

\begin{tabular}{|c|c|c|c|c|c|c|c|}
\hline & $\begin{array}{l}\text { Maximum } \\
\text { acceleration (g) }\end{array}$ & $\begin{array}{l}\text { Maximum } \\
\text { velocity }(\mathrm{m} / \mathrm{s})\end{array}$ & $\begin{array}{l}\text { Maximum } \\
\text { displacement }(\mathrm{mm})\end{array}$ & $\begin{array}{l}\text { Maximum force } \\
(N)\end{array}$ & Frequency $(\mathrm{Hz})$ & $\begin{array}{l}\text { Slope } \\
\text { (dB/Oct) }\end{array}$ & $\begin{array}{l}\text { Amplitude } \\
\left(\mathrm{g}^{2} / \mathrm{Hz}\right)\end{array}$ \\
\hline \multirow{4}{*}{$\begin{array}{l}\text { High } \\
\text { Vibration }\end{array}$} & 48 & 0.378 & 1.42 & 213 & 20 & & 0.021 \\
\hline & & & & & $20-150$ & 3 & 0.130 \\
\hline & & & & & $150-600$ & -6 & 0.130 \\
\hline & & & & & $600-2000$ & & \\
\hline \multicolumn{8}{|c|}{ Overall $G_{\mathrm{rms}}=\mathbf{1 1 . 2 8}$} \\
\hline
\end{tabular}




\begin{tabular}{|lll}
\hline Table 2. & Sequence of primers used in the qPCR experiments. \\
\hline Genes & Primers $\left(5^{\prime}-3^{\prime}\right)$ & \\
\hline runt1 & TCCTATCGGAGACGGACA & GCTTCACCGTTGACGAGT \\
egr1 & GTTAGCGTGCCATTTTTG & AGCTGCATTGATAAGGCTTC \\
fos & GAACGACGCCAATTTCAG & CGCTTCGAGTTGTTTGAGT \\
jnk & TCAACGAATCTCGGTCG & AGTGAGCTCTCTTTCATCAACC \\
yorkie & ATTTGTGTCGACTCCATCC & CCATTAAGACATGTCGACAAG \\
piwi & ATCCTATGGCACCGAATGAG & CCCTTATGCACCTTTCCAAC \\
\hline
\end{tabular}

Biosystems) by denaturation at $95^{\circ} \mathrm{C}$ for $10 \mathrm{~min}$, followed by 40 cycles at $95^{\circ} \mathrm{C}$ for $15 \mathrm{~s}$ and $60^{\circ} \mathrm{C}$ for $40 \mathrm{~s}$. Melting curve analyses were performed to verify the amplification specificity. Relative quantification of gene expression was performed according to the $\Delta \Delta-C T$ method $^{55}$ with at least two technical replicates per sample and at least two biological replicates. The measured $C_{t}$ values were normalized to the ubiquitously expressed control mRNA smed-ura4. Student t-test was used for differential expression analysis between samples. The set of used primers in $\mathrm{qPCR}$ analysis in provided in Table 2.

\section{Reporting summary}

Further information on experimental design is available in the Nature Research Reporting Summary linked to this paper.

\section{DATA AVAILABILITY}

The data that support the findings of this study are available from the corresponding author upon reasonable request.

Received: 30 March 2020; Accepted: 11 August 2020;

Published online: 08 September 2020

\section{REFERENCES}

1. Harris, B. et al. International Space Station Utilization and Advancing Research in Space. In AIAA SPACE 2013 Conference and Exposition. San Diego, CA, U.S.A., American Institute of Aeronautics and Astronautics. (2013).

2. Chang, Y.-W. The first decade of commercial space tourism. Acta Astronaut. 108, 79-91 (2015).

3. Moro-Aguilar, R. The new commercial suborbital vehicles: an opportunity for scientific and microgravity research. Microgravity Sci. Technol. 26, 219-227 (2014).

4. Cottin, H. et al. Space as a tool for astrobiology: review and recommendations for experimentations in earth orbit and beyond. Space Sci. Rev. 209, 83-181 (2017).

5. Huang, B., Li, D. G., Huang, Y. \& Liu, C. T. Effects of spaceflight and simulated microgravity on microbial growth and secondary metabolism. Mil. Med. Res 5, 18 (2018).

6. Horneck, G., Klaus, D. M. \& Mancinelli, R. L. Space microbiology. Microbiol. Mol. Biol. Rev. 74, 121-156 (2010)

7. Becker, J. L. \& Souza, G. R. Using space-based investigations to inform cancer research on Earth. Nat. Rev. Cancer 13, 315-327 (2013).

8. Beysens, D. A. \& van Loon, J. in Generation and Applications of Extra-Terrestrial Environments on Earth (eds Daniel A Beysens \& JJWA van Loon) Ch. 1, 5-9 (Rivers Publishers, 2015).

9. Najrana, T. \& Sanchez-Esteban, J. Mechanotransduction as an adaptation to gravity. Front. Pediatr. 4, 140 (2016).

10. Manzano, A. et al. Novel, Moon and Mars, partial gravity simulation paradigms and their effects on the balance between cell growth and cell proliferation during early plant development. npj Microgravity 4, 9 (2018).

11. Fitzgerald, J. \& Hughes-fulford, M. Mechanically induced c-fos expression is mediated by CAMP in MC3T3-E1 osteoblasts. FASEB J. 13, 553-557 (1999).

12. Kopp, S. et al. Thyroid cancer cells in space during the TEXUS-53 sounding rocket mission-The THYROID Project. Sci. Rep. 8, 10355 (2018).

13. Ulbrich, C. et al. Differential gene regulation under altered gravity conditions in follicular thyroid cancer cells: relationship between the extracellular matrix and the cytoskeleton. Cell Physiol. Biochem. 28, 185-198 (2011).
14. Baert, P. et al. The potential (radio-)biological impact of launch vibration. Acta Astronaut. 58, 456-463 (2006).

15. Cubano, L. A. \& Lewis, M. L. Effect of vibrational stress and spaceflight on regulation of heat shock proteins hsp70 and hsp27 in human lymphocytes (Jurkat). J. Leukoc. Biol. 69, 755-761 (2001).

16. Wehland, M. et al. The impact of altered gravity and vibration on endothelial cells during a parabolic flight. Cell Physiol. Biochem. 31, 432-451 (2013).

17. Gentile, L., Cebria, F. \& Bartscherer, K. The planarian flatworm: an in vivo model for stem cell biology and nervous system regeneration. Dis. Model Mech. 4, 12-19 (2011).

18. Saló, E. et al. Planarian regeneration: achievements and future directions after 20 years of research. Int. J. Dev. Biol. 53, 1317-1327 (2009).

19. Baguñà, J. The planarian neoblast: the rambling history of its origin and some current black boxes. Int. J. Dev. Biol. 56, 19-37 (2012).

20. Rink, J. C. Stem cell systems and regeneration in planaria. Dev. Genes evolution 223, 67-84 (2013).

21. Felix, D. A. et al. It is not all about regeneration: Planarians striking power to stand starvation. Semin. Cell. Dev. Biol. 87, 169-181 (2019).

22. Adell, T., Salo, E., van Loon, J. J. \& Auletta, G. Planarians sense simulated microgravity and hypergravity. Biomed. Res. Int 2014, 679672 (2014).

23. de Sousa, N. et al. Transcriptomic analysis of planarians under simulated microgravity or $8 \mathrm{~g}$ demonstrates that alteration of gravity induces genomic and cellular alterations that could facilitate tumoral transformation. Int. J. Mol. Sci. 20, 720 (2019).

24. Gorgiladze, G. I. Regenerative capacity of the eye of Helix lucorum in a 163-day orbital flight aboard the International Space Station. Dokl. Biol Sci. 440, 316-319 (2011).

25. Lu, H. M. et al. Effects of large gradient high magnetic field (LG-HMF) on the longterm culture of aquatic organisms: planarians example. Bioelectromagnetics 39, 428-440 (2018).

26. Morokuma, J. et al. Planarian regeneration in space: persistent anatomical, behavioral, and bacteriological changes induced by space travel. Regeneration $\mathbf{4}$, 85-102 (2017).

27. Sandmann, T., Vogg, M. C., Owlarn, S., Boutros, M. \& Bartscherer, K. The headregeneration transcriptome of the planarian Schmidtea mediterranea. Genome Biol. 12, R76 (2011).

28. Wenemoser, D., Lapan, S. W., Wilkinson, A. W., Bell, G. W. \& Reddien, P. W. A molecular wound response program associated with regeneration initiation in planarians. Genes Dev. 26, 988-1002 (2012).

29. Almuedo-Castillo, M. et al. JNK controls the onset of mitosis in planarian stem cells and triggers apoptotic cell death required for regeneration and remodeling. PLoS Genet. 10, e1004400 (2014).

30. de Sousa, N., Rodríguez-Esteban, G., Rojo-Laguna, J. I., Saló, E. \& Adell, T. Hippo signaling controls cell cycle and restricts cell plasticity in planarians. PLoS Biol. 16, e2002399 (2018).

31. Zanconato, F., Cordenonsi, M. \& Piccolo, S. YAP/TAZ at the roots of cancer. Cancer Cell 29, 783-803 (2016).

32. Gozdecka, M. \& Breitwieser, W. The roles of ATF2 (activating transcription factor 2) in tumorigenesis. (Portland Press Limited, 2012).

33. Tjandrawinata, R. R., Vincent, V. L. \& Hughes-Fulford, M. Vibrational force alters mRNA expression in osteoblasts. FASEB J. 11, 493-497 (1997).

34. Kumei, Y., Nakajima, T., Sato, A., Kamata, N. \& Enomoto, S. Reduction of G1 phase duration and enhancement of c-myc gene expression in HeLa cells at hypergravity. J. Cell Sci. 93, 221-226 (1989).

35. Nose, K. \& Shibanuma, M. Induction of early response genes by hypergravity in cultured mouse osteoblastic cells (MC3T3-E1). Exp. Cell Res. 211, 168-170 (1994).

36. de Groot, R. P. et al. Microgravity decreases c-fos induction and serum response element activity. J. Cell Sci. 97, 33-38 (1990).

37. Bacabac, R. G. et al. Bone cell responses to high-frequency vibration stress: does the nucleus oscillate within the cytoplasm? FASEB J. 20, 858-864 (2006).

38. Lützenberg, R. et al. Pathway analysis hints towards beneficial effects of longterm vibration on human chondrocytes. Cell. Physiol. Biochem. 47, 1729-1741 (2018).

39. Bacabac, R. G., Van Loon, J. J., Smit, T. H. \& Klein-Nulend, J. Noise enhances the rapid nitric oxide production by bone cells in response to fluid shear stress. Technol. Health Care 17, 57-65 (2009).

40. Van Loon, J. J. Micro-gravity and mechanomics. Gravit. Space Res. 20, 3-17 (2007).

41. van Loon, J. J., Folgering, E. H., Bouten, C. V., Veldhuijzen, J. P. \& Smit, T. H. Inertial shear forces and the use of centrifuges in gravity research. What is the proper control?. J. Biomech. Eng. 125, 342-346 (2003).

42. Elosegui-Artola, A. et al. Force triggers YAP nuclear entry by regulating transport across nuclear pores. Cell 171, 1397-1410 (2017).

43. Van Loon, J. in Biology in Space and Life on Earth. Effects of Spaceflight on Biological Systems (ed. E. Brinckmann) 17-32 (John Wiley and Sons Ltd., 2007). 
44. Guntermann, A. Untersuchungen zellulärer Proteinphosphorylierungsmuster primärer Osteoblasten nach Hypergravitationsbelastung PhD thesis, Philipps-Universität Marburg, (2002).

45. Pletser, V. \& Kumei, Y. in Generation and Applications of Extra-Terrestrial Environments on Earth (eds Daniel, A. B. \& Jack, JWA v. L.) 61-73 (Rivers Publishers, 2015).

46. von Kampen, P., Kaczmarczik, U. \& Rath, H. J. The new drop tower catapult system. Acta Astronaut. 59, 278-283 (2006).

47. Blue Origin. New Shepard Payload User's Guide. Revision E NSPM-MAD002. Texas, USA, Blue Origin Texas, LLC. 98 (2018).

48. Virgin Galactic. SpaceShipTwo: An Introductory Guide for Payload Users. Santa Fe, New Mexico, USA, Virgin Galactic. Revision Number: WEB005:34 (2016).

49. Taylor, F. W. et al. Challenges and Opportunities Related to Landing the Dream Chaser $^{\oplus}$ Reusable Space Vehicle at a Public-Use Airport. Space Traffic Management Conference, Embry-Riddle Aeronautical University, Daytona Beach, FL, USA (2014).

50. Fedele, A. et al. The Space Rider Programme: end user's needs and payload applications survey as driver for mission and system definition. Acta Astronautica 152, 534-541 (2018)

51. de Sousa, N. \& Adell, T. Maintenance of Schmidtea mediterranea in the Laboratory. Bio-Protocol. 8, 1-16 (2018).

52. van Loon, J. J. et al. The large diameter centrifuge, LDC, for life and physical sciences and technology. Life in Space for Life on Earth, Anger, France, SP-663, ESA Communication Production Office (2008).

53. Code of Federal Regulations, C. Vol. App. E 667, Table E417.611-661, Minimum Workmanship (Department of Transportation (DOT)) (2012).

54. NASA, G. S. F. C. in For GSFC Flight Programs and Projects Vol. GSFC-STD-7000A GSFC-STD-7000A (NASA GSFC Technical Standards Program, Greenbelt, 2013).

55. Livak, K. J. \& Schmittgen, T. D. Analysis of relative gene expression data using realtime quantitative PCR and the 2- $\Delta \Delta C T$ method. Methods 25, 402-408 (2001).

\section{ACKNOWLEDGEMENTS}

We appreciate the assistance of Mr. Alan Dowson at ESA-ESTEC-TEC-MMG during the various campaigns. This work was supported by BFU2017-83755-P from Ministerio de Ciencia, Innovación y Universidades (Spain) and grant 2017SGR-1455 from AQU (Generalitat de Catalunya) to T.A. and E.S. The study was also possible though an ESA CORA grant; contract no. $4000109540 / 13 / \mathrm{NL} / \mathrm{PG} / \mathrm{pt}$ and for JvL via an ESA contract 4000107455/12/NL/PA.

\section{AUTHOR CONTRIBUTIONS}

N.d.S., J.I.R.-L., E.S., T.A.: set-up and analyzed the data from the planarian experiments G.A.: overall PI of planarian study; M.C., J.V.: set-up and operation vibration study; J.J. W.A.v.L.: initiation of this particular launch load study, set-up and operations of the LDC centrifuge. All authors discussed the results and revised and edited the paper.

\section{COMPETING INTERESTS}

The authors declare no competing interests.

\section{ADDITIONAL INFORMATION}

Supplementary information is available for this paper at https://doi.org/10.1038/ s41526-020-00115-7.

Correspondence and requests for materials should be addressed to J.J.W.A.v.L.

Reprints and permission information is available at http://www.nature.com/ reprints

Publisher's note Springer Nature remains neutral with regard to jurisdictional claims in published maps and institutional affiliations.

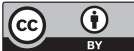

Open Access This article is licensed under a Creative Commons Attribution 4.0 International License, which permits use, sharing, adaptation, distribution and reproduction in any medium or format, as long as you give appropriate credit to the original author(s) and the source, provide a link to the Creative Commons license, and indicate if changes were made. The images or other third party material in this article are included in the article's Creative Commons license, unless indicated otherwise in a credit line to the material. If material is not included in the article's Creative Commons license and your intended use is not permitted by statutory regulation or exceeds the permitted use, you will need to obtain permission directly from the copyright holder. To view a copy of this license, visit http://creativecommons. org/licenses/by/4.0/.

(c) The Author(s) 2020 